\title{
Delayed Presentation of Congenital Jejunal Web beyond the Neonatal Period
}

\author{
Mostafa Zain Ahmed Khairi Mohamed Abouheba \\ Department of Pediatric Surgery, Faculty of Medicine, Alexandria University, Alexandria, \\ Egypt
}

\section{Keywords}

Jejunal web · Button battery · Foreign body · Intestinal obstruction

\begin{abstract}
Congenital web of the gastrointestinal tract is a rare anomaly which may present at any site of the gastrointestinal tract. In cases with an intact membrane, the presenting symptoms may take the form of complete intestinal obstruction while in other cases with a fenestrated membrane, it may present with partial intestinal obstruction such as failure to thrive, volume depletion, or poor body-weight gain, representing a chronic condition. It is very rare for a jejunal web to present with retention of accidently ingested foreign body. In this report, we document a case of 14-month boy with retention of accidently ingested button battery who was found to have a jejunal web on surgical exploration. This case report stresses on the importance of prevention of ingestion of inanimate foreign bodies especially in young infants and that the absence of symptoms does not preclude presence of foreign body in children. Also, surgeons should be prepared to deal with other unsuspected findings intraoperatively. After a review of the literature, jejunal web should be considered in the differential diagnosis of chronic partial intestinal obstruction even in adults.
\end{abstract}

\section{Introduction}

Congenital web of the gastrointestinal tract is a rare anomaly which may present at any site of the gastrointestinal tract, most commonly in the stomach and small intestine [1]. In cases with an intact membrane, the presenting symptoms may take the form of complete obstruction with vomiting (which is bilious in an obstruction distal to the opening of the ampulla of Vater), abdominal distension, and failure to pass meconium in instances of lower 
obstruction. In other cases with a fenestrated membrane, the presenting symptoms may take the form of partial obstruction such as failure to thrive, volume depletion, or poor bodyweight gain, representing a chronic condition [2].

Ingestion of batteries requires a special attention due to the risk of significant morbidityrelated release of chemicals causing tissue disintegration especially with button batteries impacted in the esophagus which require urgent removal [2]. However, if the battery is affirmed to be distal to the esophagus and the patient is asymptomatic, at that point it can be observed as $>80 \%$ of batteries which are distal to the esophagus will pass uneventfully within 48 hours [3].

It is very rare for a jejunal web to present with retention of accidently ingested foreign body. In this report, we document a case of 14 months boy with retention of accidently ingested button battery (BB) who was found to have a jejunal web on surgical exploration.

\section{Case Report}

A case of 14-month-old boy was referred to our center due to retention of a BB which was accidently ingested 3 weeks ago. The baby was playing with his toys when the mother noticed that a toy was broken and one of the batteries was missing (size $8 \mathrm{~mm}$ ). She went to the nearest hospital where an abdominal X-ray was done nearly $2 \mathrm{~h}$ after the accident and showed that the battery is beyond the esophagus and stomach (shown in Fig. 1). So, the decision was made for outpatient management and to repeat the abdominal X-ray after a week as long as the boy is asymptomatic. Follow-up X-rays were done at 1, 2, and 3 weeks later, and the battery was detected in different positions within the abdominal cavity (shown in Fig. 2).

Then, the boy was referred to our center. On examination, the child was vitally stable, abdomen was lax with mild distension, and normal stool could be detected in PR examination. Laparoscopic exploration failed to detect the site of the battery and an evident discrepancy in the jejunum with hugely dilated proximal segment up to the duodenojejunal junction was identified and brought out through a longitudinal umbilical incision (shown in Fig. 3). On palpation of the site of this discrepancy, a membrane-like thickening was felt with retained food particle proximal to it containing the battery (shown in Fig. 3). After opening the dialed segment through the antimesenteric side, the battery was taken out, revealing a web obstructing the intestinal lumen with a pinhole opening in its center (shown in Fig. 3). We resected the segment containing the discrepancy with $10 \mathrm{~cm}$ of the proximal ectatic segment, followed by end-to-end anastomosis in 2 layers.

Histological examination revealed that the web was covered with normal intestinal mucosa without a proper muscle layer between the 2 mucosal surfaces confirming the congenital nature of the web. The patient recovered uneventfully, started oral feeding on the third postoperative day, and was discharged on the sixth postoperative day. He is now doing well and free of symptom for more than 6 months after his operation.

\section{Discussion}

Intestinal (jejunoileal) atresias are classified into 4 types based on their anatomic characteristics as bowel continuity, bowel length, presence of a mesenteric defect, and the pattern of vascular supply of the bowel [4]. In type I atresia, the bowel wall and mesentery are in continuity (the proximal dilated intestine is continuous with the distal narrow one) with the lumen obstructed by a diaphragm or membrane. The diaphragm is composed of mucosa and submucosa with normal muscular walls. It can be felt as a thickened segment on palpation

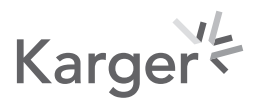


Fig. 1. The first abdominal X-ray showing that the battery is beyond the esophagus and stomach.
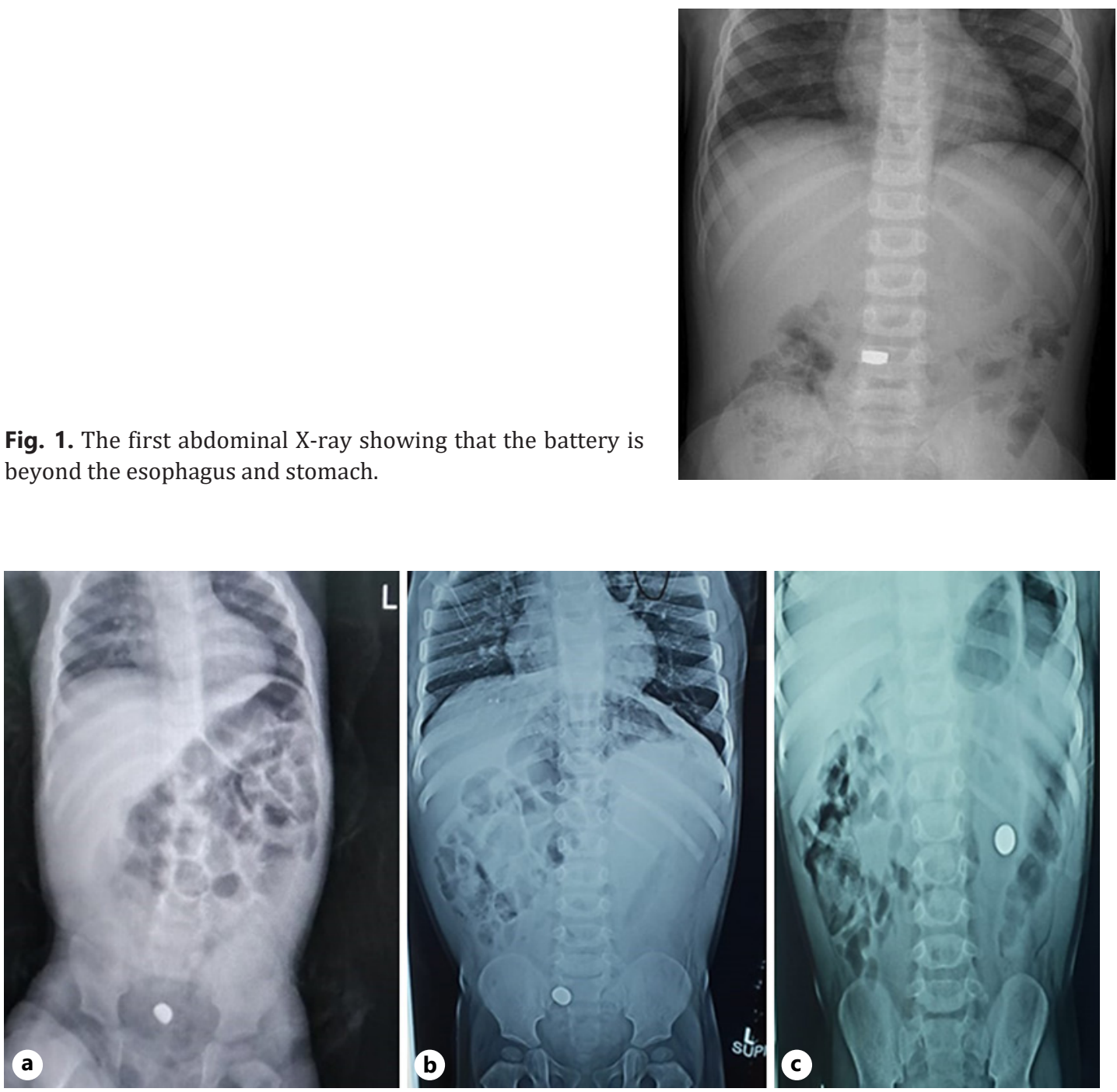

Fig. 2. Follow-up X-rays showing the battery in different positions within the abdominal cavity. At 2 weeks (a), at 4 weeks (b), and at 6 weeks (c).

from the exterior (2-3 $\mathrm{mm}$ in thickness). A web is a special subtype where the diaphragm has an aperture, which may be central or eccentric with variable diameter $[5,6]$.

Depending on the size of the aperture, intestinal webs may result in bowel obstruction whether complete neonatal intestinal obstruction or partial obstruction with symptoms as poor feeding, intermittent vomiting, and failure to thrive [2]. Cases with partial obstruction represent a diagnostic difficulty when compared with intestinal atresia as the intermittent partial obstruction or malabsorption may improve without treatment as the intestinal contents are usually liquid. Clinical investigations may be normal initially. However, these patients usually develop failure to thrive and may progress to complete intestinal obstruction requiring surgical exploration. The age of onset is inversely related to the diameter of the aperture. A diaphragm with an aperture diameter of $10 \mathrm{~mm}$ or more may go unnoticed throughout life [6].

Excluding acquired diaphragm disease related to nonsteroidal anti-inflammatory drugs, to the best of our knowledge, there are 9 reports in literature documenting congenital jejunal webs beyond the neonatal period with only 10 cases (shown in Table 1). The age range at 


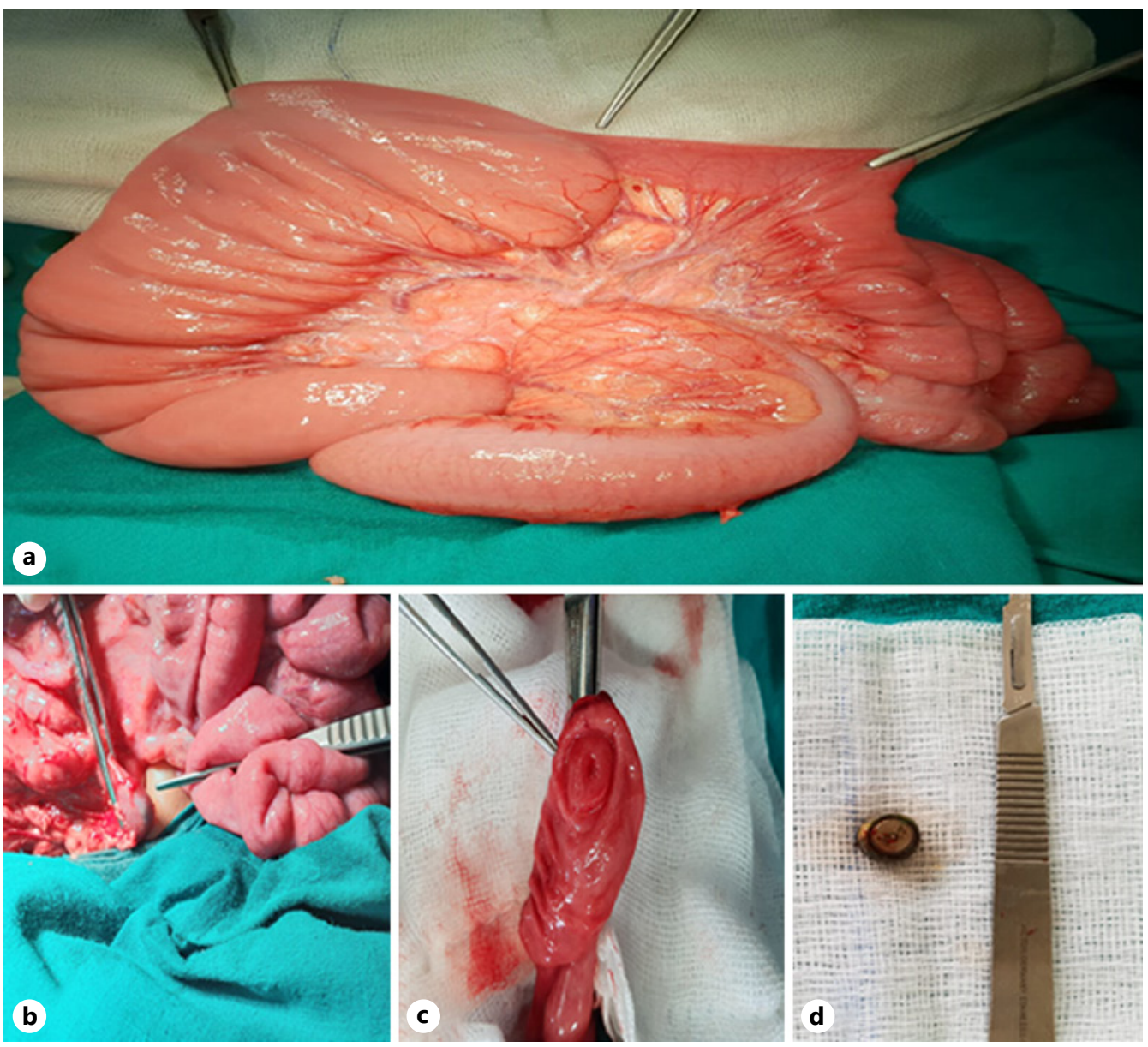

Fig. 3. Intraoperative finding. a Evident discrepancy in the proximal segment with hugely dilated proximal segment. b The battery was identified within the dilated proximal segment. c After opening the dialed segment at the antimesenteric side, a web obstructing the intestinal lumen with a pinpoint opening in its center was identified. $\mathbf{d}$ The battery after removal.

presentation was highly variable extending from 6 months up to 50 years. Seven cases presented with symptoms of chronic partial obstruction as intermittent bilious vomiting, abdominal pain, and failure to thrive, while the other 2 cases presented with impacted bezoars.

Our case presented with retention of an accidently ingested BB for 3 weeks. BBs are considered as a special group of foreign bodies due to their corrosive properties. They can damage the gastrointestinal mucosa and cause serious injury within a few hours through 3 mechanisms; leakage of battery content directly corroding adjacent mucosa, burns due to electric current, and necrosis due to direct compression $[7,8]$. Recent recommendation is BB removal within $2 \mathrm{~h}$ after ingestion in cases with esophageal impaction as mucosal lesion occurs within a very short time after ingestion; while if the BB is located in the stomach, urgent endoscopic removal would be not necessary in asymptomatic patients. However, in recent years, there are some reports of early gastric mucosal damage [9]. In our case, the first abdominal X-ray was done nearly $2 \mathrm{~h}$ after the accident and showed that the battery is beyond the esophagus and stomach (shown in Fig. 1). So, the decision was made for outpatient management and to repeat the abdominal X-ray after a week as long as the boy is asymptomatic depending on the small size of the BB $(8 \mathrm{~mm})$. However, follow-up X-rays were done 
Zain et al.: Delayed Presentation of Congenital Jejunal Web

Table 1. Cases with jejunal web presented beyond the neonatal period reported in literature

\begin{tabular}{|c|c|c|c|c|c|}
\hline Report & Year & Cases, $n$ & Age & Presentation & Management \\
\hline $\begin{array}{l}\text { Moore } \\
\text { et al. [10] }\end{array}$ & 1981 & 1 & 50 years & $\begin{array}{l}\text { Phytobezoar with colicky, peri-umbilical pain, } \\
\text { flatulence, acid reflux, and post-prandial vomiting }\end{array}$ & $\begin{array}{l}\text { Enterotomy and } \\
\text { web eaxcision }\end{array}$ \\
\hline $\begin{array}{l}\text { De Backer } \\
\text { et al. [11] }\end{array}$ & 1993 & 1 & 1 year & Intermittent bilious vomiting and failure to thrive & $\begin{array}{l}\text { Enterotomy and } \\
\text { web excision }\end{array}$ \\
\hline $\begin{array}{l}\text { Kothari } \\
\text { et al. [12] }\end{array}$ & 2003 & 1 & 4 years & $\begin{array}{l}\text { Intermittent bilious vomiting, abdominal pain, } \\
\text { and failure to thrive }\end{array}$ & $\begin{array}{l}\text { Enterotomy and } \\
\text { web excision }\end{array}$ \\
\hline $\begin{array}{l}\mathrm{Yu} \\
\text { et al. [13] }\end{array}$ & 2004 & 1 & 25 years & Enteric bezoar with abdominal pain and vomiting & $\begin{array}{l}\text { Resection with } \\
\text { end-to-end } \\
\text { anastomosis }\end{array}$ \\
\hline $\begin{array}{l}\text { Seltz } \\
\text { et al. [14] }\end{array}$ & 2008 & 1 & 13 months & $\begin{array}{l}\text { Failure to thrive and recurrent episodes of } \\
\text { nonbilious emesis from } 6 \text { months of age. }\end{array}$ & $\begin{array}{l}\text { Enterotomy and } \\
\text { web excision }\end{array}$ \\
\hline $\begin{array}{l}\text { Prabhu } \\
\text { et al. [15] }\end{array}$ & 2010 & 1 & 32 years & $\begin{array}{l}\text { Abdominal pain exacerbated by high fiber foods } \\
\text { such as fruits and vegetables. } \\
\text {-Impaction of a small bowel enteroscopy capsule. }\end{array}$ & $\begin{array}{l}\text { Enterotomy and } \\
\text { web excision }\end{array}$ \\
\hline $\begin{array}{l}\text { Lin } \\
\text { et al. [16] }\end{array}$ & 2012 & 1 & 2 years & Intermittent bilious vomiting & $\begin{array}{l}\text { Enterotomy and } \\
\text { web excision }\end{array}$ \\
\hline \multirow[t]{2}{*}{$\begin{array}{l}\text { Bhosale } \\
\text { et al. [17] }\end{array}$} & 2017 & 1 & $2^{1 / 2}$ months & $\begin{array}{l}\text { Abdominal distension and constipation since } \\
\text { birth with occasional episode of bilious vomiting }\end{array}$ & $\begin{array}{l}\text { Enterotomy and } \\
\text { web excision }\end{array}$ \\
\hline & & 1 & 6 months & Intermittent bilious vomiting & \\
\hline $\begin{array}{l}\text { Weledji } \\
\text { et al. [18] }\end{array}$ & 2020 & 1 & 19 months & $\begin{array}{l}\text { Intermittent bilious vomiting, abdominal pain, } \\
\text { and failure to thrive }\end{array}$ & $\begin{array}{l}\text { Resection with } \\
\text { side to side } \\
\text { anastomosis }\end{array}$ \\
\hline
\end{tabular}

at 1,2 , and 3 weeks later and confirmed retention of the battery, so the decision was made for exploration to remove the battery. In our case, the proximal segment was hugely dilated and ectatic, so we had to resect this segment with end-to-end anastomosis. In the reported cases, 7 cases were treated by enterotomy and web excision, while the other 2 cases were treated by resection and reanastomosis without any difference on the prognosis.

To conclude, despite its low incidence, jejunal web should be considered in the differential diagnosis of chronic partial intestinal obstruction even in adults. This case report also stresses on the importance of the prevention of ingestion of inanimate foreign bodies especially in young infants and that the absence of symptoms does not preclude presence of foreign body in children. Also, surgeons should be prepared to deal with other unsuspected findings intraoperatively.

\section{Acknowledgements}

The authors are greatly thankful to the family members of the patient for allowing us to publish this report.

\section{Statement of Ethics}

The research was conducted ethically in accordance with the World Medical Association Declaration of Helsinki. Parental written informed consent on behalf of the patient was obtained for publication of this case report and accompanying images. Approval of the Ethics 
Committee of the Faculty of Medicine was obtained, approval number (0305087). Anonymity and confidentiality of participants were maintained.

\section{Conflict of Interest Statement}

The authors have no conflicts of interest to declare.

\section{Funding Sources}

The authors received no financial support for the research, authorship, and/or publication of this article.

\section{Author Contributions}

All the authors attest that they meet the current ICMJE criteria for authorship. Concept: Ahmed Khairi. Design: Mostafa Zain, Ahmed Khairi. Materials: Mostafa Zain. Data collection and processing: Mostafa Zain. Analysis and interpretation: Mohamed Abouheba. Writer: Mostafa Zain, Mohamed Abouheba. Critical review: Ahmed Khairi.

\section{References}

1 Lloyd D, Kenny SE. Congenital anomalies. In: Walker WA, editor. Pediatric gastrointestinal disease. 4th ed. Hamilton, Ontario: BC Becker Inc.; 2004. p. 565-7.

2 Dalla Vecchia LK, Grosfeld JL, West KW, Rescorla FJ, Scherer LR, Engum SA. Intestinal atresia and stenosis: a 25-year experience with 277 cases. Arch Surg. 1998;133(5):490-7.

3 Kay M, Wyllie R. Pediatric foreign bodies and their management. Curr Gastroenterol Rep. 2005;7(3):212-8.

4 Grosfeld JL. Jejunoileal atresia and stenosis. In: O’Neill JA, Rowe MI, Grosfeld JL, Fonkalsrud EW, Coran AG, editors. Pediatric surgery. 5th ed. St. Louis: Mosby; 1998. p. 1145-58.

5 Dave S, Gupta DK. Jejunoileal atresia. In: Gupta DK, editor. Textbook of neonatal surgery. 1st ed. New Delhi: Modern Publishers; 2000. p. 181-90. book-chapter

6 Thapa BR, Sahni A, Jethi SC, Rao KL, Mehta S. Jejunal diaphragm. Indian Pediatr. 1991;28:544-6.

7 Wright CC, Closson FT. Updates in pediatric gastrointestinal foreign bodies. Pediatr Clin North Am. 2013;60: 1221-39.

8 Litovitz T, Whitaker N, Clark L. Preventing battery ingestions: an analysis of 8648 cases. Pediatrics. 2010;125: 1178-83.

9 Jatana KR, Litovitz T, Reilly JS, Koltai PJ, Rider G, Jacobs IN. Pediatric button battery injuries: 2013 task force update. Int J Pediatr Otorhinolaryngol. 2013;77(9):1392-9.

10 Moore DJ, O'Sullivan G, Hederman WP. Congenital jejunal mucosal diaphragm and phytobezoar: a cause of intermittent small bowel obstruction in an adult. Ir J Med Sci. 1981;150(1):160-1.

11 De Backer T, Voet V, Vandenplas Y, Deconinck P. Simultaneous laparotomy and intraoperative endoscopy for the treatment of high jejunal membranous stenosis in a 1-year-old boy. Surg Laparosc Endosc. 1993;3:333-6.

12 Kothari PR, Kothari NP. Jejunal web with late presentation. Indian Pediatr. 2003;40:1109-10.

13 Yu CC, Jan YJ, Cheng SB, Chen YJ, Wu CC, Liu TJ, et al. Small bowel obstruction caused by a congenital intestinal web with an enteric bezoar in an adult: report of a case. Surg Today. 2004;34(3):265-7.

14 Seltz LB. Case 1: a green case of failure to thrive. Paediatr Child Health. 2008;13:685-7.

15 Prabhu KL, Enns R, Brown CJ. Intermittent obstruction resulting from multiple intestinal webs. Can J Gastroenterol. 2010;24(2):101-2.

16 Lin HH, Lee HC, Yeung CY, Chan WT, Jiang CB, Sheu JC, et al. Congenital webs of the gastrointestinal tract: 20 years of experience from a pediatric care teaching hospital in Taiwan. Pediatr Neonatol. 2012;53(1):12-7.

17 Bhosale M. Perforated jejunal diaphragm - an unsuspected cause of intestinal obstruction in children. Niger J Surg Res. 2017;18:19-21.

18 Weledji EP, Monono N, Nana T. Late presentation of incomplete jejunal atresia. J Pediatr Surg Case Rep. 2020; 55:101413. 